\title{
PENGARUH SISTEM INFORMASI MANAJEMEN TERHADAP KEPUASAN MASYARAKAT PADA DINAS KOMUNIKASI DAN INFORMATIKA DI PUSAT PEMERINTAKOTA TANGERANG
}

\author{
Diana Sutami ${ }^{1}$ \\ H.Yusmedi Yusuf., SH., M.Si ${ }^{2}$ \\ Hilman., SE., M.Si ${ }^{3}$ \\ Fakultas Ilmu Sosial dan Ilmu Politik \\ Ilmu Administrasi Negara \\ Universitas Islam-Syekh Yusuf Tangerang \\ dianasutami@gmail.com
}

\begin{abstract}
This research is motivated by the importance of the main task and the special role of the communication and informatics center in the field of service and delivery of information for the people of the city of Tangerang. The communication and information technology center of the city government of Tangerang always strives to satisfy its people in creative and innovative ways. The purpose of this study was to determine the effect of management information systems on community satisfaction. The type of research that researchers use is quantitative research using sampling techniques that are accidental sampling techniques. Based on the results obtained in this study between management information systems and community satisfaction has a positive and significant influence on results obtained in the management information systems variable that is equal to $81 \%$ of the criteria set and the results obtained on the community satisfaction variable that is equal to $86 \%$ of the criteria set.
\end{abstract}

Keywords: Management Information Systems and Community Satisfaction

\section{Abstrak}

Penelitian ini dilatarbelakangi akan pentingnya tugas utama serta peran khusus Dinas Komunikasi dan Informatika Pusat Pemerintah Kota Tangerang dalam bidang pelayanan dan penyampaian informasi untuk Masyarakat Kota Tangerang. Dinas Komunikasi dan Informatika Pusat Pemerintah Kota Tangerang selalu berupaya untuk memuaskan Masyarakatnya dengan cara yang kreatif dan inovatif. Tujuan dari penelitian ini untuk mengetahui Pengaruh Sistem Informasi Manajemen terhadap Kepuasan Masyarakat. Jenis penelitian yang di gunakan yaitu penelitian kuantitatif dengan menggunakan teknik accidental sampling. Berdasarkan hasil yang didapat dalam penelitian ini antara Sistem Informasi Manajemen dan Kepuasan Masyarakat mempunyai pengaruh yang positif dan signifikan, hasil yang di dapat pada variabel Sistem Informasi Manajemen yaitu sebesar $81 \%$ dari kriteria yang di tetapkan, dan hasil yang di dapat pada variabel Kepuasan Masyarakat yaitu sebesar 86\% dari kriteria yang di tetapkan.

Kata Kunci: Sistem Informasi Manajemen dan Kepuasan Masyarakat

\section{PENDAHULUAN}

Salah satu organisasi kedinasan yang

mengemban tugas utama serta mempunyai

peran khusus dalam hal bidang pelayanan dan penyampaian informasi adalah Dinas

$\begin{array}{lrrr}\text { Komunikasi } & \text { dan } & \text { Informatika } & \text { Pusat } \\ \text { Pemerintah } & \text { Kota } & \text { Tangerang. } & \text { Dinas } \\ \text { Komunikasi } & \text { dan } & \text { Informatika } & \text { Pusat } \\ \text { Pemerintah } & \text { Kota } & \text { Tangerang merupakan } \\ \text { salah satu } & \text { Dinas yang selalu berupaya }\end{array}$


memuaskan Masyarakatnya dengan cara yang kreatif dan inovatif.

Kemajuan sistem informasi berbasis aplikasi yang semakin canggih dan berkembang Dinas Komunikasi dan Informatika Pusat Pemerintah Kota Tangerang belum lama ini telah mengeluarkan terobosan baru dengan meluncurkan berbagai sistem informasi berbasis aplikasi untuk kepuasan Masyarakatnya seperti: LIVE NEWS, SIHBP (SISTEM INFORMASI HARGA BAHAN POKOK), LAKSA, E-PAPER (Aplikasi Koran Digital), SIAP KERJA, PERIZINAN BERBASIS ONLINE, LAYANAN DARURAT 112, dan SIMPATI RS.

Maka dalam penelitian ini, Peneliti menjelaskan sistem informasi berbasis aplikasi yang digunakan Masyarakat Kota Tangerang dalam mengakses informasi, berikut penjelasannya:

1. Live News memainkan peran yang sangat penting untuk Masyarakat Kota Tangerang, aplikasi Live News ini berisikan tentang kumpulan berita informasi kegiatan harian di Pusat Pemerintah Kota Tangerang. Sehingga memudahkan Masyarakat Kota Tangerang untuk menjaring informasi dalam berita tersebut.
2. SIHBP (Sistem Informasi Harga Bahan Pokok) merupakan salah satu sistem informasi berbasis aplikasi untuk memantau naik turunnya harga bahan pokok kebutuhan rumah tangga.

3. LAKSA (Layanan Aplikasi Kotak Saran Anda) merupakan sistem informasi berbasis aplikasi layanan untuk Masyarakat Kota Tangerang dalam menuangkan persepsi tentang pelayanan serta sarana dan prasarana di Dinas Komunikasi dan Informatika Pusat Pemerintah Kota Tangerang.

4. E-Paper atau Aplikasi koran digital merupakan sistem informasi berbasis aplikasi koran digital yang di peruntukkan untuk Masyarakat Kota Tangerang dalam memilih dan memilah sumber informasi yang tertera di aplikasi koran digital tersebut.

5. Siap Kerja merupakan program unggulan dan upaya Pemerintah untuk membantu Masyarakat Kota Tangerang dalam mencari kerja.

6. Perizinan Berbasis Online merupakan sistem informasi berbasis aplikasi yang didukung dengan layanan-layanan online yang menjadikan sistem 
informasi berbasis aplikasi ini banyak di gandrungi oleh Masyarakat Kota Tangerang.

7. Layanan Darurat 112 merupakan sistem informasi berbasis aplikasi yang sangat dibutuhkan Masyarakat Kota Tangerang pada saat situasi dan kondisi yang sangat genting.

8. Simpati RS (Sistem Informasi Tempat Tidur Rumah Sakit) merupakan sistem informasi berbasis aplikasi penyedia tempat tidur pasien di rumah sakit untuk rawat inap.

Dari penjelasan diatas mengenai sistem informasi berbasis aplikasi, Peneliti hanya berfokus pada satu sistem saja yaitu sistem informasi berbasis aplikasi LAKSA (Layanan Aplikasi Kotak Saran Anda).

Berdasarkan latar belakang diatas, maka dapat di identifikasikan masalah sebagai berikut:

1. Bagaimana Sistem Informasi Manajemen pada Dinas Komunikasi dan Informatika di Pusat Pemerintah Kota Tangerang?

2. Bagaimana Kepuasan Masyarakat pada Dinas Komunikasi dan Informatika di Pusat Pemerintah Kota Tangerang?

$\begin{array}{llr}\text { 3. Bagaimana } & \text { Pengaruh } & \text { Sistem } \\ \text { Informasi } & \text { Manajemen } & \text { terhadap }\end{array}$
Kepuasan Masyarakat pada Dinas Komunikasi dan Informatika di Pusat Pemerintah Kota Tangerang?

4. Upaya-upaya yang di terapkan oleh Kepala Seksi Pengembangan Aplikasi pada Dinas Komunikasi dan Informatika di Pusat Pemerintah Kota Tangerang?

\section{TINJAUAN PUSTAKA}

\section{Sistem Informasi Manajemen}

Menurut Gordon B. Davis (1991), "Sistem Informasi Manajemen merupakan sebagai sebuah sistem yang memperoleh input data instruksi, melakukan pengolahan data yang di sesuaikan dengan instruksi kemudian menjadi sebuah output informasi".

Kemudian menurut George M. Scott (di terjemahkan oleh Budiman 2001:100), menjelaskan "Sistem Informasi Manajemen adalah sekumpulan sub sistem informasi menyeluruh, terkoordinasi dan secara rasional terpadu yang dapat mentransformasi data sehingga menjadi informasi lewat serangkaian cara guna meningkatkan produktivitas yang sesuai dengan sifat dan gaya manajer atas dasar kriteria mutu yang telah di sepakati”.

Selanjutnya menurut Holmes dalam Onong Sunyoto (2014:5), Sistem Informasi 
Manajemen adalah suatu sistem yang di rancang untuk menyajikan informasi pilihan yang berorientasi kepada keputusan yang di perlukan oleh manajemen guna merencanakan, mengawasi, dan menilai aktivitas organisasi. Di rancangnya itu di dalam kerangka kerja yang menitikberatkan pada perencanaan keuangan, perencanaan penampilan, dan pengawasan semua tahap.

Berdasarkan pengertian diatas, maka Peneliti dapat menyimpulkan bahwa: Sistem Informasi Manajemen merupakan suatu rangkaian kinerja yang kompleks dari setiap unit-unit yang didalamnya terdapat komponen-komponen perangkat yang menggabungkan unit dan komponen tersebut menjadi sebuah rancangan.

\section{Kepuasan Masyarakat}

Menurut Kotler, Kepuasan Masyarakat adalah tingkat perasaan senang atau kecewa seseorang yang berasal dari perbandingan antara kesannya terhadap kinerja dan harapan-harapannya. Hal ini menunjukan bahwa kepuasan masyarakat merupakan fungsi dari kesan kinerja dan harapan. Jika kinerja berada dibawah harapan, masyarakat tidak puas. Sebaliknya, jika kinerja memenuhi harapan maka masyarakat akan merasa puas.
Selanjutnya menurut Tse dan Wilton (1988) mendefinisikan

Kepuasan Masyarakat (pengguna layanan pada layanan publik) sebagai respon pengguna layanan terhadap evaluasi ketidaksesuaian (disconfirmation) yang di persepsikan dan kinerja actual yang di rasakan dan di terima oleh pengguna jasa layanan (masyarakat).

Menurut Mowen (1995:511), mendefinisikan "Kepuasan Masyarakat adalah sikap keseluruhan tentang puas atau tidaknya Masyarakat terhadap jasa atau pelayanan yang telah di berikan dan sudah di akuisisi".

Berdasarkan pengertian diatas, Peneliti dapat menyimpulkan bahwa Kepuasan Masyarakat merupakan salah satu bentuk penilaian Masyarakat kepada pihak terkait dalam hal pelayanan yang di berikan oleh pihak terkait ataupun dalam hal penyampaian informasi yang disampaikan oleh pihak terkait, apakah Masyarakat menilai pihak terkait dengan menunjukkan respon yang baik atau malah sebaliknya Masyarakat menilai pihak terkait dengan menunjukkan respon yang kurang baik.

\section{Faktor Utama Kepuasan Masyarakat}

Kepuasan Masyarakat mempunyai faktor utama yaitu sebagai berikut: 
- Kepuasan Masyarakat merupakan faktor yang sangat penting bagi Dinas Komunikasi dan Informatika Pusat Pemerintah Kota Tangerang, agar Dinas Komunikasi dan Informatika Pusat Pemerintah Kota Tangerang mengetahui seberapa puasnya Masyarakat tentang pelayanan yang di berikan dan informasi yang di sampaikan.

- Kepuasan Masyarakat menjadi landasan utama Kepala Seksi Pengembangan Aplikasi dan para Pegawai Dinas Komunikasi dan Informatika Pusat Pemerintah Kota Tangerang.

- Kepuasan Masyarakat membawa pengaruh yang positif bagi Dinas Komunikasi dan Informatika Pusat Pemerintah Kota Tangerang, agar Dinas Komunikasi dan Informatika Pusat Pemerintah Kota Tangerang selalu berupaya mementingkan dan mengutamakan kepuasan Masyarakat

\section{Kerangka Pemikiran}

Menurut Peneliti, kerangka pemikiran merupakan bentuk gagasan yang di tuangkan peneliti dalam bentuk permasalahan-permasalahan yang di dapat hasil dari penelitian di Dinas Komunikasi dan Informatika Pusat Pemerintah Kota Tangerang.

Adapun indikator teori tentang Sistem Informasi Manajemen menurut Gordon B. davis (1995:7) yaitu: (1) informasi, (2) manusia sebagai pengolah informasi (3) konsep sistem, (4) konsep organisasi dan manajemen, (5) konsep pengambilan keputusan, (6) nilai informasi.

Selanjutnya indikator teori tentang Kepuasan Masyarakat menurut Susila (2010) yaitu: (1) kepuasan masyarakat atas pengetahuan, kemampuan, kesopanan, dan dapat di percaya dari aparat (pegawai dinas), (2) kepuasan Masyarakat atas pemberian info yang baik dan jelas oleh aparat (pegawai dinas), (3) kepuasan Masyarakat untuk pelayanan yang cepat dan akurat oleh aparat (pegawai dinas), (4) kepuasan Masyarakat atas perhatian dan kepedulian aparat (pegawai dinas).

\section{Hipotesis}

Menurut Peneliti, hipotesis merupakan kajian dalam bentuk dugaan sementara yang dilakukan Peneliti, untuk memperoleh data dan informasi dengan cara melakukan observasi lapangan, wawancara dengan Kepala Seksi Pengembangan 
Aplikasi Dinas Komunikasi dan Informatika

Pusat Pemerintah Kota Tangerang.

400

Berdasarkan pengertian tentang hipotesis yang di kemukakan oleh Peneliti, maka Peneliti membuat hipotesis kajian sementara yaitu: "Terdapat Pengaruh Positif Dan Signifikan Antara Sistem Informasi Manajemen Terhadap Kepuasan Masyarakat Pada Dinas Komunikasi Dan Informatika Di Pusat Pemerintah Kota Tangerang".

$$
\begin{aligned}
& =\frac{1+\left(400 \times\left(0,1^{2}\right)\right)}{400} \\
& =\frac{1+400 \times(0,01)}{400} \\
& =\quad \frac{1+(4,00)}{400} \\
& =\quad 4
\end{aligned}
$$

\section{METODE PENELITIAN}

\section{Populasi dan Sampel}

Populasi dan sampel dalam penelitian ini adalah Masyarakat Kota Tangerang yang di targetkan Peneliti berjumlah 400 orang. Maka untuk menentukan jumlah yang sebenarnya, Peneliti menggunakan rumus sederhana menurut (Notoatmodjo, 2009:92).

Rumus sederhana menurut Notoatmodjo (2009:92) yaitu:

$$
\mathrm{n}=\frac{\mathrm{N}}{1+\mathrm{N}\left(\mathrm{d}^{2}\right)}
$$

Keterangan:

$\mathrm{n}$ : $\quad$ Besar sampel

$\mathrm{N}$ : Besar populasi

d: Tingkat kepercayaan atau ketepatan yang di inginkan (10\%) 


\section{Operasional Variabel}

Operasional Variabel merupakan salah satu fokus yang di gunakan peneliti untuk menganalisis kedua variabel penelitian yaitu variabel bebas dan variabel terikat guna memperoleh gambaran apakah kedua variabel penelitian tersebut dapat berpengaruh signifikan atau tidak signifikan.

\section{HASIL PENELITIAN DAN PEMBAHASAN}

Pada BAB ini, Peneliti akan menguraikan variabel $X$ (Sistem Informasi Manajemen dan variabel Y (Kepuasan Masyarakat) serta menganalisis data yang di peroleh dari penyebaran angket penelitian dalam bentuk pernyataan di Dinas Komunikasi dan Informatika Pusat Pemerintah Kota Tangerang. Adapun judul yang mendasari penelitian tersebut, yaitu Pengaruh Sistem Informasi Manajemen terhadap Kepuasan Masyarakat. Data yang di peroleh dalam penelitian ini yaitu observasi, wawancara, dan penyebaran angket kepada 80 orang responden (Masyarakat Kota Tangerang).

\section{Uji Validitas \\ Selanjutnya dilakukan uji validitas dan reliabilitas dari alat ukur yang di gunakan dalam penelitian ini. Uji validitas dan reliabilitas pada kuesioner dilakukan}

untuk mengetahui apakah skor kuesioner tersebut berdistribusi valid dan berdistribusi reliabel atau tidak.

Berdasarkan hasil dari rekapitulasi jawaban responden setelah dilakukan pengolahan data dan pengujian data dengan menggunakan program SPSS versi 21.0, di dapat keputusan uji dengan menggunakan teknik korelasi product moment yaitu sebagai berikut:

Bila $\mathrm{r}$ hitung > $\mathrm{r}$ tabel, maka Ho ditolak artinya valid

Bila $r$ hitung $<\mathrm{r}$ tabel, maka Ho diterima artinya tidak valid

Adapun untuk mengetahui $r$ tabel berikut Peneliti sajikan rumus menentukan $r$ tabel yaitu:

\section{Rumus:}

$\mathrm{Df}=\mathrm{n}-2$

\section{Keterangan:}

Df :Degree of Freedom (derajat bebas)

N :Jumlah Responden

2 :Variabel Penelitian (X dan Y)

Jumlah Responden $=80$

Taraf Signifikansi uji t dua sisi $=2,5 \%$ atau $(0,025)$
Df $=\mathrm{n}-2$
$80-2=78$
Df $\quad=78$
$\mathrm{r}$ tabel $=0,219$ 
Hasilnya dari dua variabel X (Sistem Informasi Manajemen) dan variabel $\mathrm{Y}$ (Kepuasan Masyarakat) dengan jumlah 80 responden dari 400 sampel dan taraf signifikansi 0,025 di dapatkan nilai $t$ tabelnya yaitu 0,219 .

\section{Uji Reliabilitas}

Selanjutnya dilakukan uji validitas dan reliabilitas dari alat ukur yang di gunakan dalam penelitian ini. Uji validitas dan reliabilitas pada kuesioner dilakukan untuk mengetahui apakah skor kuesioner tersebut berdistribusi valid dan berdistribusi reliabel atau tidak.

Untuk mengetahui reliabilitas, dilakukan dengan cara membandingkan antara skor masing-masing variabel dengan skor total. Kuesioner penelitian dinyatakan reliabilitas apabila skor variabel tersebut berkorelasi secara signifikan dengan skor totalnya.

Adapun keputusan uji untuk reliabilitas yaitu sebagai berikut:

Bila a cronbach's $>\mathrm{r}$ tabel, maka Ho ditolak artinya reliabel

Bila a cronbach's $<\mathrm{r}$ tabel, maka Ho diterima artinya tidak reliabel

Berdasarkan keputusan uji product moment, berikut ini adalah tabel hasil perhitungan untuk uji reliabilitas:
TABEL

\section{Hasil SPSS untuk Reliabilitas}

Sistem Informasi Manajemen (X)

Reliability Statistics

\begin{tabular}{|r|c|c|}
\hline $\begin{array}{c}\text { Cronbach's } \\
\text { Alpha }\end{array}$ & $\begin{array}{c}\text { Cronbach's } \\
\text { Alpha Based } \\
\text { on } \\
\text { Standardized } \\
\text { Items }\end{array}$ & $\begin{array}{c}\text { N of } \\
\text { Items }\end{array}$ \\
\hline, 709 &, 710 & 6 \\
\hline
\end{tabular}

Sumber: hasil perhitungan SPSS 21.0

Jika Cronbach's alpha berpengaruh positif dan bobot dari $r$ tabel lebih besar maka variabel $X$ (Sistem Informasi Manajemen) dinyatakan reliabel.

Berikut peneliti sajikan tabel perbandingan cronbach's alpha dengan $r$ tabel yang tertera pada tabel sebagai berikut:

TABEL

Perbandingan Cronbach's Alpha dengan r Tabel

\begin{tabular}{|c|c|c|c|}
\hline $\begin{array}{c}\text { Cronbach's } \\
\text { alpha }\end{array}$ & $\begin{array}{c}\text { r } \\
\text { tabel }\end{array}$ & Hasil & $\begin{array}{c}\text { Keterang } \\
\text { an }\end{array}$ \\
\hline 0,709 & 0,219 & $\begin{array}{c}\text { Cronba } \\
\text { ch's } \\
\text { alpha }> \\
\text { r tabel }\end{array}$ & Reliabel \\
\hline
\end{tabular}

Dari tabel perbandingan cronbach's alpha dengan $r$ tabel yang peneliti sajikan diatas, maka kuesioner dari variabel Sistem Informasi Manajemen (X) dinyatakan reliabel.

\section{Uji Validitas}

Selanjutnya dilakukan uji validitas dan reliabilitas dari alat ukur yang di gunakan dalam penelitian ini. Uji validitas 
dan reliabilitas pada kuesioner dilakukan untuk mengetahui apakah skor kuesioner tersebut berdistribusi valid dan berdistribusi reliabel atau tidak.

Berdasarkan hasil rekapitulasi jawaban responden setelah dilakukan pengolahan data dengan program SPSS versi 21.0, di dapat keputusan uji dengan menggunakan teknik korelasi product moment yaitu sebagai berikut:

Bila $r$ hitung > $r$ tabel, maka Ho ditolak artinya valid

Bila $r$ hitung $<r$ tabel, maka Ho diterima artinya tidak valid

\section{Uji Reliabilitas}

Selanjutnya dilakukan uji validitas dan reliabilitas dari alat ukur yang di gunakan dalam penelitian ini. Uji validitas dan reliabilitas pada kuesioner dilakukan untuk mengetahui apakah skor kuesioner tersebut berdistribusi valid dan berdistribusi reliabel atau tidak.

Untuk mengetahui reliabilitas, dilakukan dengan cara membandingkan antara skor masing-masing variabel dengan skor total. Kuesioner penelitian dinyatakan reliabilitas apabila skor variabel tersebut berkorelasi secara signifikan dengan skor totalnya. Berdasarkan keputusan uji product moment, berikut ini adalah tabel hasil perhitungan untuk uji reliabilitas:

Adapun keputusan uji untuk reliabilitas yaitu sebagai berikut:

Bila a cronbach's $>r$ tabel, maka Ho ditolak artinya reliabel

Bila a cronbach's $<\mathrm{r}$ tabel, maka Ho diterima artinya tidak reliabel

Berdasarkan keputusan uji product moment, berikut ini adalah tabel hasil perhitungan untuk uji reliabilitas:

TABEL

Hasil SPSS untuk Reliabilitas

Kepuasan Masyarakat (Y)

\begin{tabular}{|r|c|r|}
\hline \multicolumn{3}{|c|}{ Reliability Statistics } \\
\hline $\begin{array}{c}\text { Cronbach's } \\
\text { Alpha }\end{array}$ & $\begin{array}{c}\text { Cronbach's } \\
\text { Alpha Based } \\
\text { on } \\
\text { Standardize } \\
\text { d Items }\end{array}$ & $\begin{array}{c}\text { N of } \\
\text { Items }\end{array}$ \\
\hline, 786 &, 786 & 4 \\
\hline
\end{tabular}

Sumber: hasil perhitungan SPSS 21.0

Jika Cronbach's alpha berpengaruh positif dan bobot dari $r$ tabel lebih besar maka variabel Y (Kepuasan Masyarakat) dinyatakan reliabel.

Berikut peneliti sajikan tabel perbandingan cronbach's alpha dengan $r$ tabel yang tertera pada tabel sebagai berikut: 
TABEL

Perbandingan Cronbach's Alpha dengan r Tabel

\begin{tabular}{|c|c|c|c|}
\hline $\begin{array}{c}\text { Cronbach } \\
\text { s alpha }\end{array}$ & $\begin{array}{c}\mathbf{r} \\
\text { tabel }\end{array}$ & Hasil & $\begin{array}{c}\text { Keteranga } \\
\mathbf{n}\end{array}$ \\
\hline 0,786 & 0,21 & $\begin{array}{c}\text { Cronbach } \\
\text { 's alpha }> \\
\text { r tabel }\end{array}$ & Reliabel \\
\hline
\end{tabular}

Dari tabel perbandingan cronbach's alpha dengan $r$ tabel yang peneliti sajikan diatas, maka kuesioner dari variabel Kepuasan Masyarakat (Y) dinyatakan reliabel.

\section{Uji Normalitas Data}

Pengujian normalitas data digunakan untuk menguji apakah data kontinu berdistribusi normal sehingga analisis dengan menggunakan korelasi pearson product moment persyaratannya terpenuhi. Data dikatakan berdistribusi normal bila kurva memiliki kemiringan yang seimbang dari sisi 0 rumus product moment di atas, diketahui koefisien korelasi sebesar 0,952. Hal ini pun dapat dibuktikan pada hasil olah data Program SPSS For Windows Versi 21, seperti tertera pada tabel dibawah ini:
TABEL HASIL UJI KOEFISIEN KORELASI VARIABEL X DAN VARIABEL Y

\begin{tabular}{|c|c|c|c|}
\hline \multicolumn{4}{|c|}{ Correlations } \\
\hline & & $\mathbf{X}$ & $\mathbf{Y}$ \\
\hline \multirow{3}{*}{$\mathbf{X}$} & $\begin{array}{l}\text { Pearson } \\
\text { Correlation }\end{array}$ & 1 & ,007 \\
\hline & Sig. (2-tailed) & & ,952 \\
\hline & $\mathbf{N}$ & 80 & 80 \\
\hline \multirow{3}{*}{$\mathbf{Y}$} & $\begin{array}{l}\text { Pearson } \\
\text { Correlation } \\
\end{array}$ & ,007 & 1 \\
\hline & Sig. (2-tailed) &, 952 & \\
\hline & $\mathbf{N}$ & 80 & 80 \\
\hline
\end{tabular}

Sumber : Output Data Program SPSS for Windows Versi 21, Hasil Penelitian 2019

\section{Koefisien Determinasi $\left(\mathbf{r}^{2}\right)$}

Setelah diketahui koefisien korelasi di atas, maka untuk mengetahui seberapa kuat kontribusi variabel Sistem Informasi Manajemen Terhadap Kepuasan Masyarakat, selanjutnya dapat dihitung dengan menggunakan rumus koefisien determinasi $\left(\mathrm{KD}=\mathrm{r}^{2} \mathrm{x} 100 \%\right)$ sebagai berikut:

$$
\begin{aligned}
\mathrm{KD}= & 0,952^{2} \times 100 \% \\
= & 0,9063 \times 100 \% \\
= & 0,9063 \% \text { di bulatkan menjadi } \\
& 0,096
\end{aligned}
$$

\section{Uji Hipotesis ( $\mathbf{t}_{\text {hitung }}$ )}

Selanjutnya untuk mengetahui apakah korelasi tersebut signifikan atau tidak maka perlu diuji signifikannya. 


\section{Uji Regresi Linier}

Regresi bertujuan untuk mengetahui arah hubungan antara satu variabel terhadap variabel lain, dalam hal ini yaitu untuk mengetahui Pengaruh Sistem Informasi Manajemen terhadap Kepuasan Masyarakat pada Dinas Komunikasi dan Informatika di Pusat Pemerintah Kota Tangerang.

Persamaan regresi linier sederhana yang diketahui digunakan untuk melakukan prediksi (ramalan) bagaimana individu dalam variabel dependen (Kepuasan Masyarakat) akan terjadi peningkatan bila individu dalam variabel independen (Sistem Informasi Manajemen) ditetapkan. Jadi, bila Sistem Informasi Manajemen lebih ditingkatkan sebesar 1 point, maka Kepuasan Masyarakat akan baik menjadi:

$$
\begin{aligned}
\hat{Y} & =17,063+(0,069 \times 1) \\
\hat{Y} & =17,063+0,069 \\
& =17,132
\end{aligned}
$$

Diperkirakan Kepuasan Masyarakat akan naik sebesar 17,132 jika Sistem Informasi Manajemen berubah 1 point atau Kepuasan Masyarakat akan naik bila Sistem Informasi Manajemen lebih ditingkatkan. Hal ini membuktikan bahwa variabel independen $(\mathrm{X})$ searah terhadap naiknya dan turunnya variabel dependen $(\mathrm{Y})$.
7. Upaya-Upaya yang di Terapkan oleh Kepala Seksi Pengembangan Aplikasi Pada Dinas Komunikasi dan Informatika Pusat Pemerintah Kota Tangerang

Berdasarkan hasil penelitian dan wawancara dengan Kepala Seksi Pengembangan Aplikasi, ada upaya-upaya yang di terapkan oleh Kepala Seksi Pengembangan Aplikasi pada Dinas Komunikasi dan Informatika di Pusat Pemerintah Kota Tangerang yaitu sebagai berikut:

1. Kepala Seksi Pengembangan Aplikasi harus bisa menyampaikan informasi yang jelas untuk Masyarakat Kota Tangerang, agar Masyarakat Kota Tangerang mudah memahami maksud dari informasi tersebut.

2. Kepala Seksi Pengembangan Aplikasi harus bisa memberikan contoh yang baik untuk Masyarakat Kota Tangerang agar Masyarakat Kota Tangerang lebih bijak lagi dalam menggunakan media sosial.

3. Kepala Seksi Pengembangan Aplikasi dan para pegawainya harus bisa bekerjasama dengan baik untuk meningkatkan pelayanan kepada Masyarakat Kota Tangerang 
khususnya pelayanan tentang informasi.

\section{KESIMPULAN DAN SARAN}

\section{Kesimpulan}

Berdasarkan hasil penelitian dan pembahasan mengenai Pengaruh Sistem Informasi Manajemen terhadap Kepuasan Masyarakat pada Dinas Komunikasi dan Informatika di Pusat Pemerintah Kota Tangerang, Peneliti dapat menarik kesimpulan yaitu sebagai berikut:

1. Sistem Informasi Manajemen berpengaruh terhadap Kepuasan Masyarakat, hasil yang didapatkan yaitu sebesar $81 \%$ dari kriteria yang ditetapkan.

2. Kepuasan Masyarakat berpengaruh sangat signifikan, hasil yang di dapatkan yaitu sebesar $86 \%$ dari kriteria yang ditetapkan.

3. Berdasarkan hasil yang di peroleh dari variabel Sistem Informasi Manajemen dan Kepuasan Masyarakat maka terdapat hubungan yang kuat sesuai dengan hasil yang di dapatkan dari koefisien korelasi sebesar 0,952 atau $95 \%$. Sedangkan hasil dari koefisien determinasi $\left(\mathrm{r}^{2}\right)$ adalah $0,9063^{2}$ atau 0,096 dengan demikian, variabel Sistem Informasi
Manajemen memberikan pengaruh yang sangat signifikan terhadap Kepuasan Masyarakat sebesar 0,096\% sedangkan $91,46 \%$ masih dipengaruhi oleh variabel-variabel lain. Dengan demikian hipotesis yang Peneliti kemukakan memang terbukti kebenarannya.

4. Pengaruh Sistem Informasi Manajemen terhadap Kepuasan Masyarakat pada Dinas Komunikasi dan Informatika di Pusat Pemerintah Kota Tangerang yaitu positif dan signifikan, hal ini ditunjukan oleh hasil perhitungan SPSS yang menunjukan $\mathrm{t}$ hitung $(3,846)>\mathrm{t}$ tabel $(0,219)$, maka Ho ditolak dan $\mathrm{Ha}$ diterima. Hal ini memang terdapat pengaruh yang positif dan signifikan antara Sistem Informasi Manajemen dan Kepuasan Masyarakat pada Dinas Komunikasi dan Informatika di Pusat pemerintah Kota Tangerang.

5. Persamaan regresi linear, jika variabel Sistem Informasi Manajemen ditingkatkan 1 point maka variabel Kepuasan Masyarakat meningkat sebesar 17,132. Dengan demikian variabel dependen searah terhadap naiknya variabel independen. 


\section{Saran}

Berdasarkan kesimpulan diatas, Peneliti dapat mengemukakan saran berkaitan dengan Sistem Informasi Manajemen terhadap Kepuasan Masyarakat pada Dinas Komunikasi dan Informatika di Pusat Pemerintah Kota Tangerang, sebagai berikut: 1) Kepala Seksi Pengembangan Aplikasi perlu memberikan pemahaman dan pengetahuan untuk para pegawai Dinas Komunikasi dan Informatika Pusat Pemerintah Kota Tangerang agar pegawai Dinas Komunikasi dan Informatika Pusat pemerintah Kota Tangerang mempunyai bekal dan pedoman untuk meningkatkan kemampuan dalam berkomunikasi dengan Masyarakat Kota Tangerang. 2) Kepala Seksi Pengembangan Aplikasi menyarankan para pegawai Dinas Komunikasi dan Informatika Pusat Pemerintah Kota Tangerang untuk menguasai prosedur dan tata cara kerja yang baik di Dinas Komunikasi dan Informatika Pusat Pemerintah Kota Tangerang. 3) Kepala Seksi Pengembangan Aplikasi perlu melakukan sosialisasi antar pegawai Dinas Komunikasi dan Informatika Pusat Pemerintah Kota Tangerang dalam usaha meningkatkan sistem pelayanan informasi untuk Masyarakat Kota Tangerang

\section{DAFTAR PUSTAKA}

Atmosudirdjo. (Edisi Revisi Seri Pustaka Ilmu Administrasi VII). Pengertian Administrasi.

Drs. H. Malayu S.P. Hasibuan. MANAJEMEN (Dasar Pengertian, dan Masalah).

Sugiyono. 2012. Metode Penelitian Kuantitatif, Kualitatif dan $R \& D$. Bandung: CV. Alfabeta.

Al-Qur'an Surat Al-A'raaf Ayat 52 (yang berkaitan dengan informasi).

Danu 2008 Teori Dasar Sistem Informasi Manajemen.

Melalui https://bangdanu.wordpress.com/2008/08/21 /teori-dasar-sistem-informasi-manajemensim.

Rani Nuraeni (tanpa tahun). Kepuasan Masyarakat. Melalui $<$ https://raninuraeni379.wordpress.com/kuli ah/administrasi-publik/indeks-kepuasanmasyarakat-ikm-dasar-sistem-informasimanajemen-sim>.

Dedy Londong 2012 Pengertian Kepuasan Pelanggan (Masyarakat). Melalui

$<$ https://dedylondong.blogspot.com/2012/04 -kepuasan-pelanggan-customer.html?m=1>.

Magdalena Crismalahera. Melalui <https://magdalenacrismalahera.blogspot.co $\mathrm{m} / 2013 / 10 / \mathrm{v}$-siklus-informasi

behaviorurldefaultvmlo.html?m=1>

$<$ https://www.diskominfo.tangerangkota.go. id>

Fahry Akbar Wiranda. Melalui $<$ https://ejournal3.undip.ac.id/index.php/jiab /article/view/8872/ Pengaruh Sistem Informasi Manajemen dan Lingkungan Kerja terhadap Kinerja Karyawan PT. PLN (PERSERO) Distribusi JakartaRaya 
